Article

\title{
Dental Condition as A Factor Modifying the Transmission of the Sound Vibration in the Skull Bones
}

\author{
Slawomir Balinski ${ }^{1}$, Monika Morawska-Kochman ${ }^{2, * \mathbb{D}}$, Romuald Bolejko ${ }^{3}$, Krzysztof Dudek ${ }^{4}$ \\ and Marek Bochnia ${ }^{5}$ \\ 1 Dental-prosthetic Laboratory, 1 Maja 7/1C, 58-100 Swidnica, Poland; slawomirbalinski@gmail.com \\ 2 Department of Otolaryngology, Faculty of Medicine, Wroclaw Medical University, Head and Neck Surgery, \\ Borowska 213, 50-556 Wroclaw, Poland \\ 3 Institute of Telecommunications, Teleinformatics and Acoustics, Wroclaw University of Science and \\ Technology, Wybrzeze Wyspianskiego 27, 50-370 Wroclaw, Poland; romuald.bolejko@pwr.edu.pl \\ 4 Faculty of Mechanical Engineering, Wroclaw University of Science and Technology, Smoluchowskiego 48, \\ 50-372 Wroclaw, Poland; krzysztof.dudek@pwr.edu.pl \\ 5 Department of Otolaryngology, Faculty of Dentistry, Wroclaw Medical University, Head and Neck Surgery, \\ Borowska 213, 50-556 Wroclaw, Poland; marek.bochnia@umed.wroc.pl \\ * Correspondence: mkochman@mp.pl; Tel.: +48-717-343-700
}

Received: 2 August 2020; Accepted: 10 September 2020; Published: 17 September 2020

\begin{abstract}
Dental deficiencies coexist with hearing loss, and dental treatment can improve hearing acuity. To prove that different dentition affects the transmission of acoustic vibrations through bone conduction, we prepared six dry human skulls to reconstruct teeth and soft tissues. We measured the transmission of vibrations from the maxilla to the cochlea, in the toothless jaw (TJ), jaw with lateral defects with frame dentures (FD), toothless jaw with complete dentures (CD), and jaw with reconstructed dentition (RD). Each skull was flexibly suspended. The maxilla was stimulated with the bone vibrator Radioear B71. The vibrations of the pyramid were measured perpendicularly using the Polytec PSV-400-M2 scanning vibrometer. Characteristics of frequencies differed simultaneously on the left (l) and right (r) side of each skull. In all states (from $234 \mathrm{~Hz}$ to $5 \mathrm{kHz}$ ), we identified 10-21 resonant (R) and 9-21 antiresonant (AR) frequencies unilaterally (+/- 5\%). In about $30 \%$ of cases, they were each time inconsistent with the "physiological" state-RD. In the $500 \mathrm{~Hz}-2 \mathrm{kHz}$ frequency range (necessary for understanding speech), the effective vibrations velocities vRMS ( $\mathrm{mm} / \mathrm{s}$ ) near cochlea were significantly lower in $\mathrm{RD}$ than in tree states, where (depending on the dentures) the least energy reached cochlea in FD and the most in TJ.
\end{abstract}

Keywords: stomatognathic system; dentition; bone conduction; hearing; acoustic signal

\section{Introduction}

The human body continuously stays in and is affected by the sound field. Generated here, acoustic vibrations are transmitted through the air, bone, and soft tissue conduction (AC, BC, and STC). The final stimulation of hearing receptor (HR) results from various complex combinations of tones added in perilymph as well constructively as destructively [1-4]. The teeth are a surprisingly active place to stimulate HR [5]. If, e.g., the Weber test results are not precise, it is recommended to place a tuning fork to the teeth [6,7]. Brown [8], at the end of the 1960s, presented results of his research on dentaural hearing. Dahlin et al. [9] continued the studies, and its interesting application as a wireless intraoral hearing aid was reported at the University of California. Although the way of passing acoustic energy from the teeth to the inner ear has not yet been precisely determined, Semczuk, in the middle of the 
last century, for the first time, observed that the presence of natural or artificial teeth changes the conduction of sounds into the ear [10]. After analyzing 5000 cases, he reported that tooth diseases and dental defects are frequently correlated with hearing disorders [11,12]. Moreover, Schell et al. [13], Lawrence et al. [14], and Peeters et al. [15] found a relationship between the reduced number of teeth and increased hearing thresholds. Kempf et al. [16] found pathologies of the dentognathic system in $80 \%$ of patients with inner ear diseases. Pihut et al. [17] reported similar functional disorders in $30 \%$ of patients with varied auriculo-vestibular symptoms. Dental treatment can improve hearing. In 1974, King et al. [18] examined two patients who underwent complete prosthetic treatment, finding that hearing thresholds for AC and BC were lower. Kempf et al. [16] reported diminished inner ear symptoms in more than $50 \%$ of patients after recommended dental treatment. The authors also observed that proper chewing might be beneficial for preventing hearing loss $[19,20]$. The reports on hearing improvement after dental treatment are still presenting [21]. We assumed that different state of dentition might affect BC. To prove that, we examined dry skulls whose physical properties were indeed different than that of living people. Some procedures, such as the removal and re-implantation of complete dental arches could, however, be performed only in vitro.

\section{Materials and Methods}

\subsection{Materials}

We used six dry and undamaged human skulls without mandibles but with preserved maxillary teeth. It was possible to make the modeled teeth similar to their natural equivalents in terms of weight and length. The study material came from the collections of the Department of Human Anatomy at Medical University. The experiment was approved by the local Bioethics Committee of Medical University (No. KB-139/2015).

Age of the examined skulls (30-50 years) was determined based on the overgrowth of sutures, sex by analyzing sex-dimorphic differences. Skulls were weighed without teeth, and their circumferences were measured as a line going from the center of the forehead, passing just above the ear canal openings, over the occiput, and back to the forehead (Table 1).

Table 1. Characteristics of the skulls.

\begin{tabular}{lcccccc}
\hline \multicolumn{1}{c}{ Skull N $^{\circ}$} & $\mathbf{1}$ & $\mathbf{2}$ & $\mathbf{3}$ & $\mathbf{4}$ & $\mathbf{5}$ & $\mathbf{6}$ \\
\hline Sex & M & W & W & M & M & W \\
\hline Mass (g) & 518 & 402 & 442 & 583 & 639 & 438 \\
\hline Circumference (mm) & 491 & 458 & 481 & 504 & 511 & 480 \\
\hline
\end{tabular}

We examined six skulls in 4 states of dentition: (a) TJ, graphical record—red, (b) RD—black (jaw with reconstructed and (almost) complete dentition, 14 teeth: four incisors, two canines, four premolars, four molars), (c) FD-green, reconstructed anterior teeth (incisors and canines) and lateral defects, supplemented with frame denture, (d) CD—purple, toothless with a complete denture.

\subsection{Methods}

The applied dentures and reconstructed tissues had been made of conventional materials and technologies used in dental prosthodontics laboratories. Tissue-resembling physical properties of reconstructed structures and mass stability over time were required.

The anatomical length of each tooth was kept. Natural teeth weighed from $550 \mathrm{mg}$ to $2450 \mathrm{mg}$, so lighter reconstructed teeth were loaded with lead $(125-500 \mathrm{mg})$ and smoothed out. Restoring soft tissues, we put a dental elastic silicone impression material into the alveolus and then placed there a corresponding tooth. The mucous membrane of the alveolar process and the palate was reconstructed 
with dental impression material too. In this model, we made acrylic typical complete denture and standard frame denture with metal frame and eight acrylic posterior teeth (Figure 1).
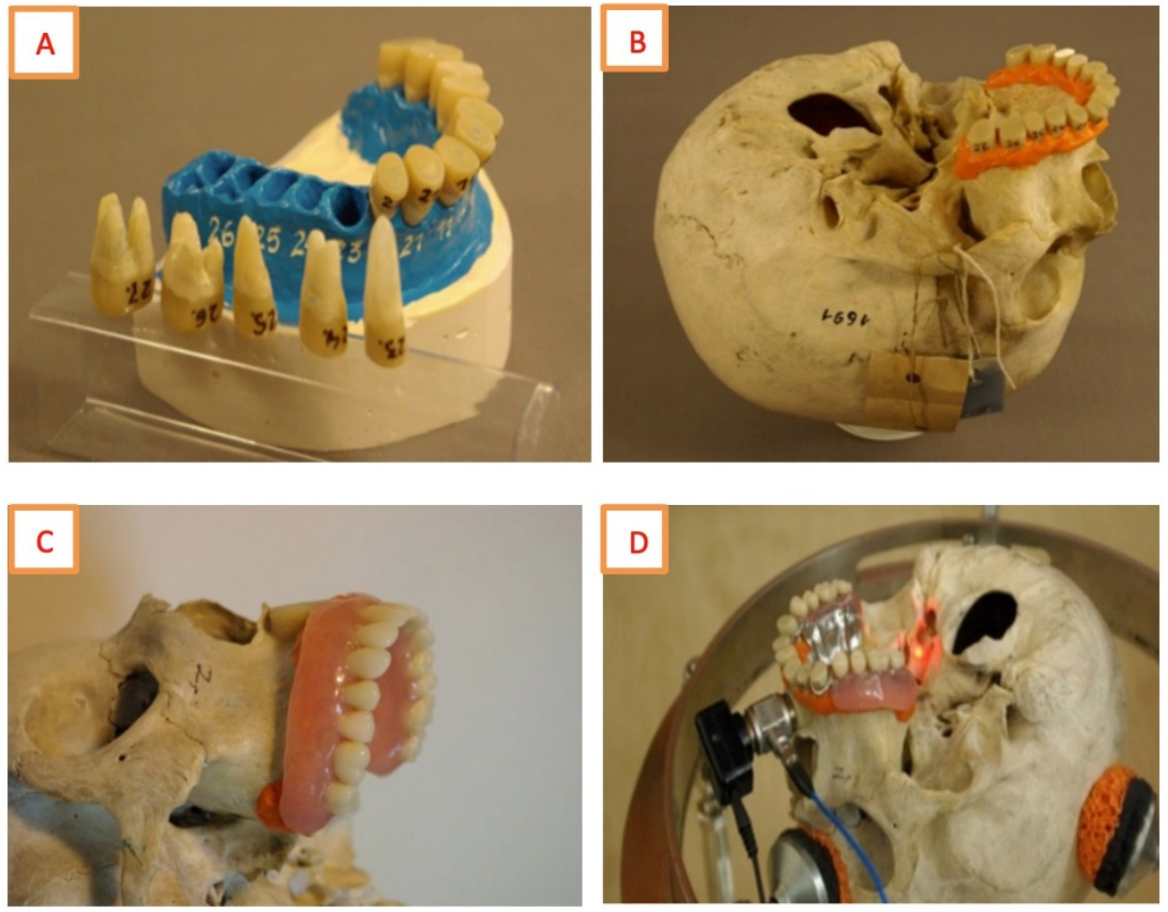

Figure 1. (A) Gypsum model with reconstructed teeth, (B) Reconstructed teeth on the reconstructed gingiva, (C) The skull with a complete denture, (D) The skull with a frame denture.

A micro-mirror $(2 \times 2 \mathrm{~mm}$ of square reflective foil) was glued (cyanoacrylate glue) in the plane of the cochlea. We made a 13-mm diameter round stand of light-curing composite on the center of the alveolar process. The inductor was fixed with wax. The skull was stimulated with Radioear B71 bone vibrator provided with sinusoidal signal tuned in the frequency range of $100 \mathrm{~Hz}-5 \mathrm{kHz}$, so-called "chirp" signal (2 V amplitude). A force converter PCB 086C01 was placed between the bone vibrator and the skull. A voltage proportional to the speed of surface displacement appeared at the output of the laser vibrometer.

A stable steel skull holding stand weighing $19.6 \mathrm{~kg}$, with adjustable height (300-380 mm), was constructed on a circular, 360-mm diameter base [22]. The following conditions: (a) stable and free positioning of the skull, (b) obtaining measurable and reproducible clamping force of the skull, (c) eliminating skull movements when modifying the state of dentition were guaranteed. Each skull was successively placed with the base (alveolus) upward and fixed, pressed down with its weight. An inductor was attached to the holder on the jaw. The laser beam was directed at the micro-mirror.

Each skull was stimulated in the same order, which minimized the number of assembly steps: (a) toothless jaw, (b) toothless jaw with CD, (c) assembling 14 reconstructed teeth, (d) disassembling premolars and molars (leaving incisors and canines) and applying FD. Induced vibrations of the petrous part of the temporal bone were using Laser Doppler Scanning Vibrometer PSV400-M2 Polytec GmbH, Waldbronn, Germany) equipped with OFV-5000 Controller, Junction Box PSV-E-400 and a scanning head PSV-i-400. Surface displacement, velocity, and acceleration are measured collinearly with the beam direction and up to 160 million times per second. Fast, precise, and non-contact vibration measurement, which enables vibration animation and identification of resonances, was the reason for choosing this device.

In the examined dentition, the measurement time was about $2 \times 2 \min$ (bilaterally). Each measurement was repeated 20 times and averaged (Figure 2). 

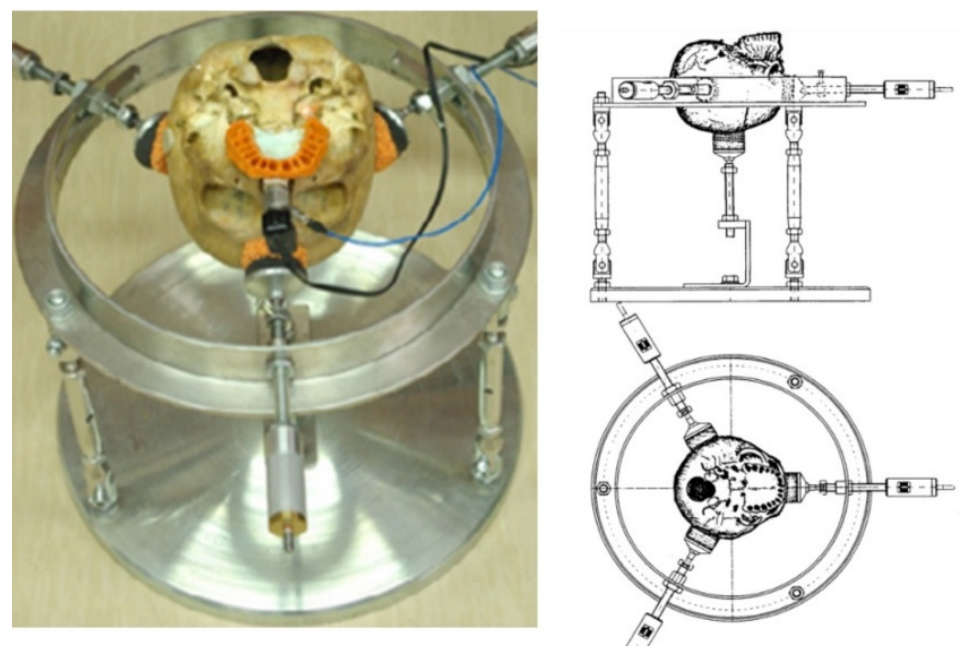

Figure 2. The skull fixed on a stand.

The obtained measurements were processed to determine the vibration transmittance, i.e., the ratio of Laplace transform of output to Laplace transform of input when all initial conditions were assumed zero. The safe margin of measurement above the background noise level is $10 \mathrm{~dB}$ [23]. In the test room, the sound pressure level $(260 \mathrm{~Hz}-8 \mathrm{kHz})$ never exceeded $35 \mathrm{~dB}$ (the sound pressure meter Robotron 00017, Dresden, Germany).

Several additional tests were performed, e.g., we checked the influence of $200 \mathrm{~g}$ load added on the jaw in RD, FD, and CD and observed no significant morphological changes in vibrations of the examined dentition. We also showed that the presence of 6 anterior natural teeth in FD does not determine measurement data.

\subsection{Statistical Analysis}

All calculations were performed using STATISTICA v. 12.5 and the EXCEL spreadsheet. We using the Kolmogorov-Smirnov and Wilcoxon's test. We also used the Friedman test to compare variables with a distribution significantly different from the norm in more than two groups. The Kruskal-Wallis test, which compares several independent groups with a distribution significantly different from normal, and the Dun test, which is a post-hoc test, were used for multiple comparisons of average ranks for all samples.

\section{Results}

\subsection{Morphological Assessment of Recordings}

Forty-eight graphical records of characteristics of vibration transmittance for six skulls, bilaterally, in 4 dentition states, in $234-508 \mathrm{~Hz}$ to $5 \mathrm{kHz}$ frequency bands were collected (Figure 3). We observed similar recordings for FD, CD, and TJ on the same side. Simultaneously, frequency characteristics of transmittance were significantly different on the 1 and $\mathrm{r}$ side of each skull in each state of dentition.

Changes in skull vibration diagrams became visible from the first detected frequencies of resonance (R) or antiresonance (AR), which were typical for all four states in the 234-508 Hz frequency range. In higher frequencies, vibration diagrams in different dentitions did not overlap, and Rs and ARs frequencies were generally different. From a standard R or AR frequency, which was present between $917 \mathrm{~Hz}$ and $1819 \mathrm{~Hz}$, the same side vibration diagrams became similar. The range of different frequencies was determined individually for the 1 and $\mathrm{r}$ side of each skull. It was identical bilaterally and called "the range of differences" (Table 2). 

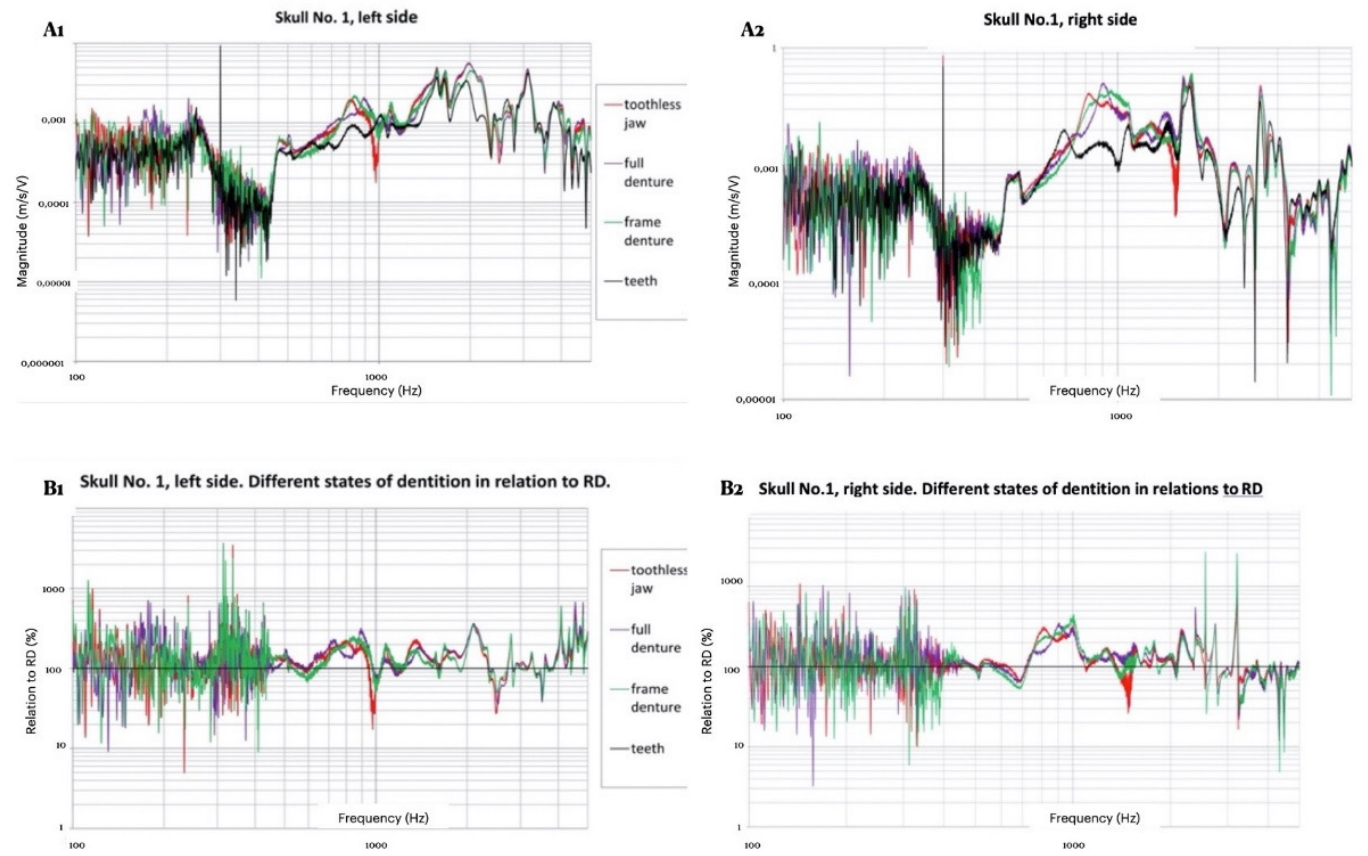

Figure 3. (A1,A2): Frequency characteristics of transmittance (vibration velocity in the cochlear area in comparison to exciting the inductor on the jaw) in different states of dentition for left and right side. (B1,B2): Differences between transmittances in different states of dentition concerning RD. Logarithmic scale for " $\mathrm{X}$ " and " $\mathrm{Y}$ " axis for left and right side.

Table 2. Limit values of "ranges of differences".

\begin{tabular}{ccccccc}
\hline Skull N & $\mathbf{1}$ & $\mathbf{2}$ & $\mathbf{3}$ & $\mathbf{4}$ & $\mathbf{5}$ & $\mathbf{6}$ \\
\hline \multirow{2}{*}{ Left side } & R: $470 \mathrm{~Hz}$ & R: $234 \mathrm{~Hz}$ & R: $426 \mathrm{~Hz}$ & AR: $501 \mathrm{~Hz}$ & AR: $507 \mathrm{~Hz}$ & R: $425 \mathrm{~Hz}$ \\
& R: $1546 \mathrm{~Hz}$ & R: $956 \mathrm{~Hz}$ & R: $1354 \mathrm{~Hz}$ & R: $1616 \mathrm{~Hz}$ & R: $1819 \mathrm{~Hz}$ & AR: $1334 \mathrm{~Hz}$ \\
\hline \multirow{2}{*}{ Right side } & R: $504 \mathrm{~Hz}$ & R: $237 \mathrm{~Hz}$ & R: $426 \mathrm{~Hz}$ & AR: $505 \mathrm{~Hz}$ & AR: $508 \mathrm{~Hz}$ & R: $421 \mathrm{~Hz}$ \\
& R: $1635 \mathrm{~Hz}$ & R: $917 \mathrm{~Hz}$ & AR: $1373 \mathrm{~Hz}$ & R: $1678 \mathrm{~Hz}$ & R: $1818 \mathrm{~Hz}$ & AR: $1251 \mathrm{~Hz}$ \\
\hline
\end{tabular}

The maximum frequency values in standard Rs and ARs were generally slightly different in each state of dentition. We reported them adopting thresholds for RD (Figure 4).
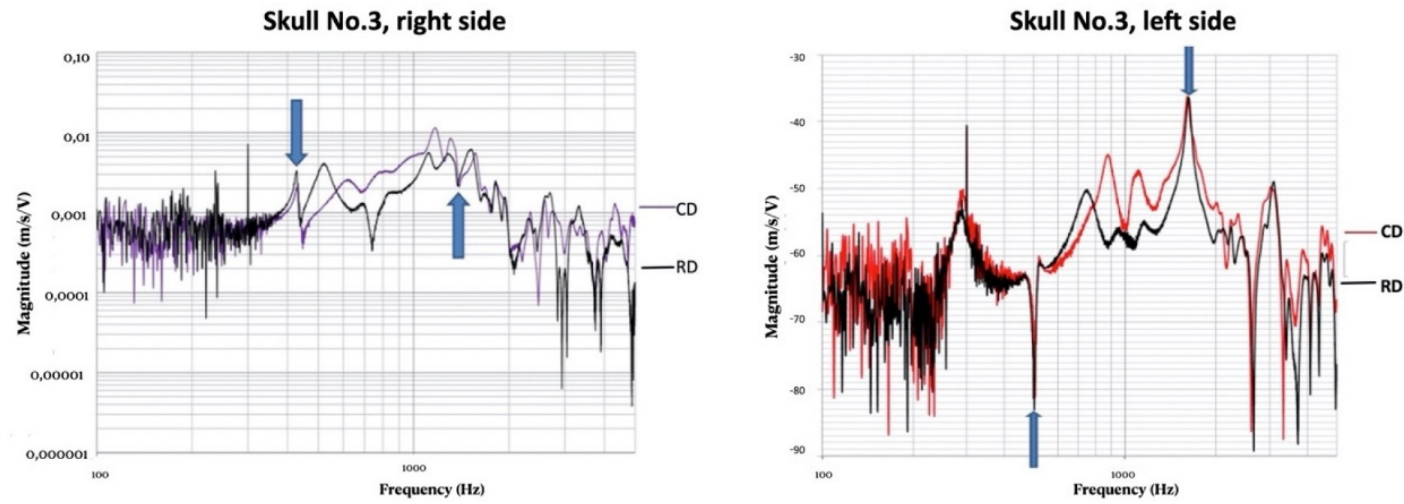

Figure 4. Vibration velocity in CD vs. RD and TJ vs. RD. The "ranges of differences" were noted. 
We considered $\mathrm{R}$ as a segment of recording characterized by bilaterally increased local amplitude surrounded by at least $2.5 \mathrm{~dB}$ declines. The value of $\mathrm{R}$ frequency was assumed as the maximum amplitude within this segment of the signal. ARs frequencies were determined in the same way, but including local minima's with "surrounding" values. If a diagram of $\mathrm{R}$ or AR in TJ, CD, or FD did not correspond with $R$ or $A R$ in $R D$, we reported it as incompatible with $R D$ (" $R \neq R D$ ” and $A R \neq$ $\left.R D^{\prime \prime}\right)$. Additionally, $R \neq R D$ was understood as the one whose frequency range corresponded with the resonance of RD but in its surrounding an AR of RD was found. ARs were evaluated similarly. Analyzing all 48 examinations of skulls in readable recordings, we unilaterally identified 10-21 Rs and 9-21 ARs. In the "range of differences" values, the border values were not included (Table 3).

Table 3. The number of Rs and ARs in each state of dentition and percentage of Rs and ARs with RD for TJ, CD, and FD. Full ranges and the "ranges of differences" values.

\begin{tabular}{|c|c|c|c|c|c|c|c|c|c|c|c|c|c|c|c|c|}
\hline \multirow{4}{*}{ Skull $\mathbf{N}^{\circ}$} & \multicolumn{16}{|c|}{ RESONANCE (R) } \\
\hline & \multicolumn{4}{|c|}{ RD } & \multicolumn{4}{|c|}{$\mathrm{TJ}$} & \multicolumn{4}{|c|}{$\mathrm{CD}$} & \multicolumn{4}{|c|}{ FD } \\
\hline & \multicolumn{2}{|c|}{$\begin{array}{c}\text { Full } \\
\text { Range }\end{array}$} & \multicolumn{2}{|c|}{$\begin{array}{c}\text { Range of } \\
\text { Differences }\end{array}$} & \multicolumn{2}{|c|}{$\begin{array}{l}\text { Full } \\
\text { Range }\end{array}$} & \multicolumn{2}{|c|}{$\begin{array}{c}\text { Range of } \\
\text { Differences }\end{array}$} & \multicolumn{2}{|c|}{$\begin{array}{c}\text { Full } \\
\text { Range }\end{array}$} & \multicolumn{2}{|c|}{$\begin{array}{c}\text { Range of } \\
\text { Differences }\end{array}$} & \multicolumn{2}{|c|}{$\begin{array}{c}\text { Full } \\
\text { Range }\end{array}$} & \multicolumn{2}{|c|}{$\begin{array}{c}\text { Range of } \\
\text { Differences }\end{array}$} \\
\hline & 1 & $\mathbf{r}$ & 1 & $\mathbf{r}$ & 1 & $\mathbf{r}$ & 1 & $\mathbf{r}$ & 1 & $\mathbf{r}$ & 1 & $\mathbf{r}$ & 1 & $\mathbf{r}$ & 1 & $\mathbf{r}$ \\
\hline 1 & 14 & 17 & 2 & 4 & 13 & 17 & 2 & 2 & 13 & 16 & 2 & 2 & 14 & 16 & 2 & 2 \\
\hline 2 & 19 & 18 & 4 & 3 & 20 & 21 & 5 & 5 & 20 & 19 & 3 & 3 & 19 & 16 & 4 & 4 \\
\hline 3 & 16 & 14 & 2 & 3 & 17 & 18 & 3 & 5 & 15 & 15 & 2 & 3 & 12 & 16 & 2 & 2 \\
\hline 4 & 12 & 11 & 2 & 1 & 11 & 13 & 3 & 2 & 11 & 11 & 3 & 2 & 11 & 12 & 3 & 2 \\
\hline 5 & 13 & 12 & 1 & 1 & 15 & 12 & 1 & 1 & 14 & 11 & 2 & 1 & 14 & 11 & 1 & 1 \\
\hline 6 & 16 & 11 & 2 & 2 & 12 & 12 & 3 & 2 & 14 & 10 & 2 & 1 & 16 & 11 & 2 & 2 \\
\hline $1-6$ & 90 & 83 & 13 & 14 & 88 & 93 & 17 & 17 & 87 & 82 & 14 & 12 & 86 & 82 & 14 & 13 \\
\hline $\begin{array}{l}\text { Mean for } \\
\text { A Skull }\end{array}$ & & & & & & & & & & & & & & & & \\
\hline \multirow{4}{*}{ Skull $\mathbf{N}^{\circ}$} & \multicolumn{16}{|c|}{ ANTIRESONANCE (AR) } \\
\hline & \multicolumn{4}{|c|}{ RD } & \multicolumn{4}{|c|}{$\mathrm{TJ}$} & \multicolumn{4}{|c|}{$\mathrm{CD}$} & \multicolumn{4}{|c|}{ FD } \\
\hline & \multicolumn{2}{|c|}{$\begin{array}{c}\text { Full } \\
\text { Range }\end{array}$} & \multicolumn{2}{|c|}{$\begin{array}{c}\text { Range of } \\
\text { Differences }\end{array}$} & \multicolumn{2}{|c|}{$\begin{array}{c}\text { Full } \\
\text { range }\end{array}$} & \multicolumn{2}{|c|}{$\begin{array}{c}\text { Range of } \\
\text { Differences }\end{array}$} & \multicolumn{2}{|c|}{$\begin{array}{c}\text { Full } \\
\text { Range }\end{array}$} & \multicolumn{2}{|c|}{$\begin{array}{c}\text { Range of } \\
\text { Differences }\end{array}$} & \multicolumn{2}{|c|}{$\begin{array}{c}\text { Full } \\
\text { Range }\end{array}$} & \multicolumn{2}{|c|}{$\begin{array}{c}\text { Range of } \\
\text { Differences }\end{array}$} \\
\hline & 1 & $\mathbf{r}$ & 1 & $\mathbf{r}$ & 1 & $\mathbf{r}$ & 1 & $\mathbf{r}$ & 1 & $\mathbf{r}$ & 1 & $\mathbf{r}$ & 1 & $\mathbf{r}$ & 1 & $\mathbf{r}$ \\
\hline 1 & 12 & 16 & 3 & 5 & 12 & 16 & 2 & 1 & 12 & 15 & 2 & 2 & 13 & 15 & 2 & 2 \\
\hline 2 & 20 & 19 & 3 & 3 & 20 & 21 & 6 & 6 & 20 & 18 & 4 & 4 & 20 & 16 & 5 & 5 \\
\hline 3 & 16 & 14 & 3 & 3 & 16 & 18 & 4 & 5 & 14 & 15 & 3 & 3 & 11 & 16 & 3 & 5 \\
\hline 4 & 12 & 11 & 2 & 1 & 13 & 13 & 3 & 2 & 11 & 12 & 3 & 2 & 11 & 12 & 2 & 2 \\
\hline 5 & 14 & 13 & 1 & 1 & 16 & 13 & 2 & 1 & 15 & 12 & 2 & 1 & 15 & 11 & 1 & 1 \\
\hline 6 & 16 & 10 & 2 & 1 & 13 & 12 & 2 & 2 & 14 & 9 & 2 & 1 & 16 & 10 & 2 & 2 \\
\hline $1-6$ & 90 & 83 & 14 & 14 & 90 & 93 & 19 & 17 & 86 & 81 & 16 & 13 & 86 & 80 & 15 & 17 \\
\hline $\begin{array}{l}\text { Mean for } \\
\text { A Skull }\end{array}$ & \multicolumn{2}{|c|}{14.4} & & & & & & & & & & & & & & \\
\hline
\end{tabular}

\subsection{Measurement Results}

The root means square velocity values vRMS $(\mathrm{mm} / \mathrm{s})$ recorded in the cochlear area were statistically analyzed. We assessed the range of undisturbed bilateral ( 1 and $r$ ) recordings from $450-500 \mathrm{~Hz}$ to $5 \mathrm{kHz}$, which were typical for six skulls in four states of dentition.

We performed a verification of the hypothesis that vibration velocity vRMS is generally distributed on the 1 and $\mathrm{r}$ side of each skull. The distributions differed significantly from the normal distribution $(p<0.01)$ and were asymmetrical. Therefore, for further analyses, we introduced non-parametric tests.

We verified the hypothesis about the lack of difference between the average vRMS value of the same skull bilaterally in 4 states of dentition. The pair order test for dependent groups confirmed 
that differences between the median velocity of vibrations both on the 1 and $\mathrm{r}$ side were statistically significant (the level of significance $\alpha=0.05$ was arbitrarily determined).

Results confirmed that vibrations in each skull and each state of dentition were characterized by high individual variability. The vibration characteristics visibly moved towards lower velocities from similar TJ, and CD, via FD to RD.

Comparing the velocity of vibrations transmitted in different teeth conditions, consistent results in both tests were obtained when we analyzed the entire frequency range divided into three bands $1.5 \mathrm{kHz}$ wide (Tables 4 and 5; Figure 5).

Table 4. Basic statistics of effective vibration velocity vRMS $(\mathrm{mm} / \mathrm{s})$ measured on the left and right side of 6 skulls in 1500-Hz frequency bands in different states of dentition. Kruskal-Wallis test results. Significant differences of at least $p<0.05$ were noted.

\begin{tabular}{|c|c|c|c|c|c|c|}
\hline \multirow{2}{*}{$\begin{array}{c}\text { Frequency Band } \\
{[\mathrm{kHz}]}\end{array}$} & \multirow[b]{2}{*}{ Statistics } & \multicolumn{4}{|c|}{ Dentition } & \multirow[t]{2}{*}{$p$-Value } \\
\hline & & Toothless Jaw & $\begin{array}{l}\text { Complete } \\
\text { Denture }\end{array}$ & $\begin{array}{c}\text { Frame } \\
\text { Denture }\end{array}$ & Teeth & \\
\hline $0.5 \div 2.0$ & $M e\left(Q_{1} \div Q_{3}\right)$ & $4.72(3.26 ; 5.49)$ & $4.67(3.38 ; 5.56)$ & $4.17(3.27 ; 4.64)$ & $3.33(2.5 ; 3.97)$ & 0.038 \\
\hline $2.0 \div 3.5$ & $M e\left(Q_{1} \div Q_{3}\right)$ & $1.67(1.13 ; 2.21$ & $1.65(0.95 ; 2.31)$ & $1.61(1.13 ; 2.16)$ & $1.49(0.99 ; 2.02)$ & 0.940 \\
\hline $3.5 \div 5.0$ & $M e\left(Q_{1} \div Q_{3}\right)$ & $0.86(0.53 ; 1.14)$ & $1.00(0.74 ; 1.19)$ & $0.96(0.69 ; 1.11)$ & $0.82(0.42 ; 0.99)$ & 0.466 \\
\hline
\end{tabular}

Me-median; Q1-lower quartile; Q3-upper quartile; min-minimum value; max-maximum value; $p$-Kruskal-Wallis test.

Table 5. The result of multiple comparisons of the effective value of vRMS in the $500 \mathrm{~Hz}-2 \mathrm{kHz}$ frequency band in skulls with RD vs. skulls with TJ, CD, and FD with the Dunn test. Significant differences of at least $p<0.05$ were noted.

\begin{tabular}{ccccc}
\hline & TJ & CD & FD & RD \\
\cline { 2 - 5 } & $\mathbf{M e}=\mathbf{4 . 7 2}$ & $\mathbf{M e}=\mathbf{4 . 6 7}$ & $\mathbf{M e}=\mathbf{4 . 1 7}$ & $\mathbf{M e}=\mathbf{3 . 3 3}$ \\
\hline TJ & & $p=1.000$ & $p=0.866$ & $p=0.028$ \\
\hline CD & $p=1.000$ & & $p=0.273$ & $p=0.018$ \\
\hline FD & $p=0.866$ & $p=0.273$ & & $p=0.033$ \\
\hline RD & $p=0.028$ & $p=0.018$ & $p=0.033$ & \\
\hline
\end{tabular}

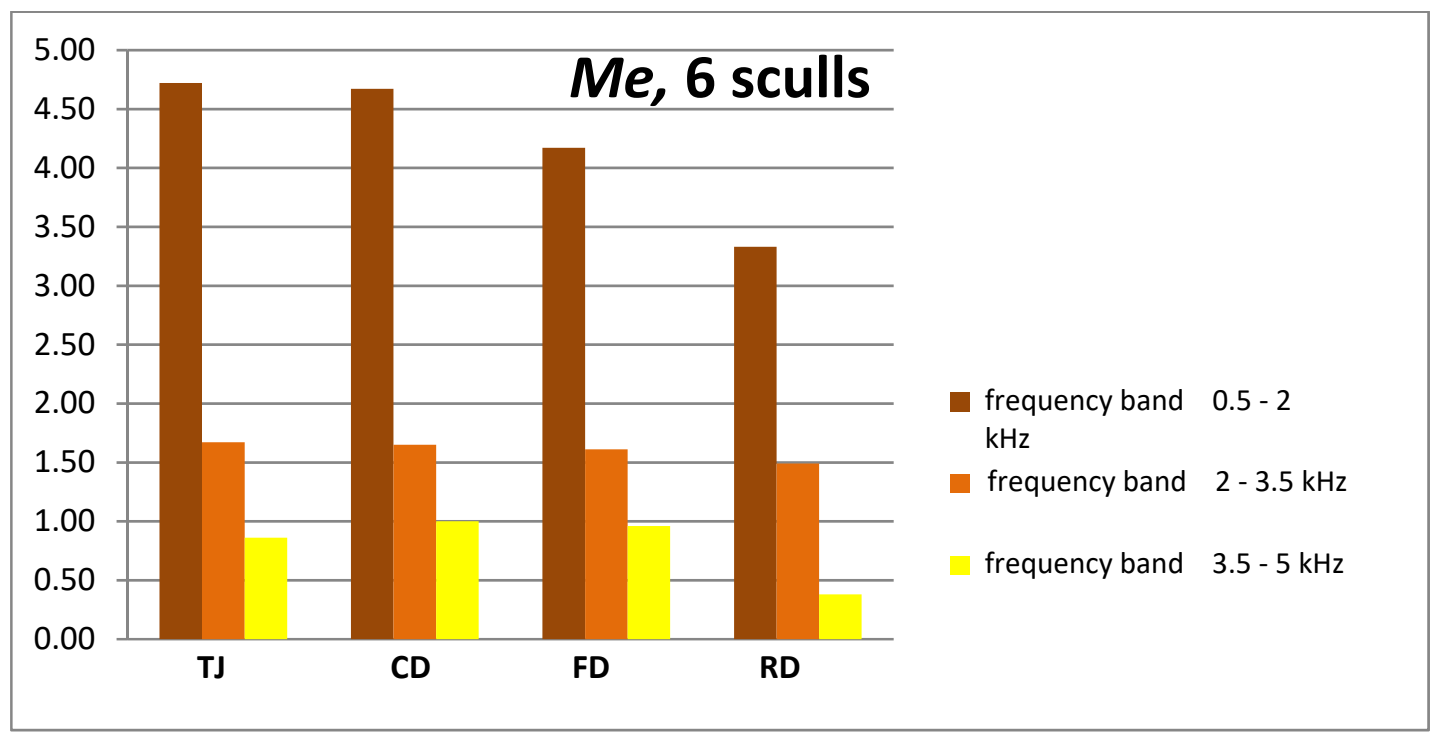

Figure 5. Me-comparison of effective vibration velocity vRMS $(\mathrm{mm} / \mathrm{s})$ measured on the 1 and $\mathrm{r}$ side of 6 skulls in the $1.5 \mathrm{kHz}$ bands. Four states of dentition (column chart). 
At least a twofold decrease in vibration velocity for frequencies above $2 \mathrm{kHz}$ is well visible. The two-fold decrease in linear amplitude is a change of $-6 \mathrm{~dB}$.

The example of measurement recording, made in the same method for mastoid is included in the Supplementary Materials.

\section{Discussion}

Currently, a direct translation of bone cochlear vibrations levels into auditory impressions is impossible. However, to approximate the level of excitation, we can measure the amplitude of vibration around the moving spatially cochlea [24-26]. Even when measurements are taken at one point and one direction, the loss of information is insignificant [1,27-29]. The human skull is a system with a large number of resonant frequencies that oscillate in the acoustic field [24,30,31]. At the lowest frequencies, the skull moves as a whole [27,32]. From $300-400 \mathrm{~Hz}$ to above $1 \mathrm{kHz}$, the skull vibrates as a mass-spring system and its large parts, e.g., temporal bone, mandible, maxilla, or even sets of teeth move in phase [33,34]. Next, between 1 and $2 \mathrm{kHz}$, the dominant system of vibrating elements becomes to be affected, and finally, only above $6 \mathrm{kHz}$ dominated by wave transmission [2]. Characteristics of the human skull vibrations and efficiency of HR stimulation depends on the area that the acoustic wave reaches $[2,27]$. We have not yet found any study in which vibrations would be applied to the most pronounced massif of the face, i.e., the jaw [24,28].

The study evaluates the morphology of speed vibrations records around the cochlea after applying vibrations to the alveolar process in different states of dentition. Rs and ARs frequencies, which constitute individual features of the human skull, were taken into account. Each skull showed high individual variability of the recorded vibration velocities. The differences between the frequencies of their $r$ and 1 side were statistically significant. Simultaneously, we observed several regularities, e.g., similar recordings in TJ, CD, and FD, with RD being distinguishable, which may be the first sign suggesting that patients' teeth are essential in the process of hearing. In the ranges of readable records, we determined unilaterally 10-21 Rs and 9-21 ARs, respectively. Our results are similar to those reported by Håkansson et al. [24]. Frequencies of the Rs and ARs in TJ, CD, and FD only slightly $(+/-5 \%)$ differed. In about $30 \%$ of cases, however, they were each time inconsistent with the "physiological" state-RD. Changes in the recording of vibration velocity depending on the state of dentition were most pronounced in the so-called "range of differences". For instance, in TJ, the number of Rs and ARs increased there by about $25 \%$.

Moreover, the number of frequency incompatibilities Rs and ARs (pathological vs. physiological status) was very high—each time over 70\%. Dentures significantly reduced differences. Thus, TJ could be considered as the most different, and FD and CD as more similar to the physiological RD.

Up to about $2 \mathrm{kHz}$, skull segments vibrate separately with teeth, both natural and reconstructed, being one of them. The statistical analysis showed that at such frequencies, the state of dentition most noticeably impacts the transmission of vibrational energy from the jaw to the HR. The lowest amount of energy is transmitted in skulls with $\mathrm{RD}$, the highest in skulls with TJ. Thanks to dentures, the conditions of vibration transmission become similar to the physiological state.

The entire frequency spectrum of speech lies between $100 \mathrm{~Hz}-9 \mathrm{kHz}$, the $500 \mathrm{~Hz}-2 \mathrm{kHz}$ band is the most important for speech understanding. The highest percentage of comprehensible words lies subsequently in the range of $1.3-1.6 \mathrm{kHz}[35,36]$.

Our work has two main limitations: a relatively small number of collected measurements and conducting tests on dry skulls, not on cadaver heads, or on heads of living persons.

The small number of samples tested (six skulls, 12 bilateral measurements) is, in our opinion, a relative limitation of our study, because the reason is ethical difficulties in obtaining material, and the similar scientific papers reports are based on an equal number of samples [33,37,38].

It has been proven that sound conduction through the skin and soft tissues is weaker by about $15 \mathrm{~dB}$. In our experiments, we used only dry sculls. Studies by Stenfelt et al., Stenfelt and Goode, and Eeg-Olofsson et al. were based on dry skulls and cadaver heads at the promontory site. It was 
assumed that the vibrations measured at the promontory, reflected probably quite well the real auditory sensations for bone conduction in the living persons. Based on this works, we assumed that despite the impact of the soft tissues covering both the jaw and the mastoid, the results for bone vibration and sound conduction would be similar $[28,39,40]$.

Considering this particularly important social efficiency range from $500 \mathrm{~Hz}$ to $2 \mathrm{kHz}$, the differences in vibration velocity around the cochlea between the "physiological" state and 3 "pathological" states are highest, and each time statistically significant. Hypothesizing, in dental pathologies, the relationship between stimuli reaching the cochlea simultaneously through different routes may be probably disrupted, and stimulation of HR is disorganized.

Recently, the government of Peru launched an instructional campaign under the slogan "Always with a Smile." This is especially important given the fact that, in this country, about $90 \%$ of the population suffers from dental problems. One of the campaign's assumptions is to improve Peruvians' hearing [41].

Supplementary Materials: The following are available online at http://www.mdpi.com/2076-3417/10/18/6478/s1, Figure S1: Frequency characteristics of transmittance (vibration velocity in the cochlear area in comparison to exciting the inductor on the mastoid) in different states of dentition for left side, Figure S2: The effective vibration velocity vRMS (mm/s) measured on the left side of skull No1 in the $500 \mathrm{~Hz}$ bands. Four states of dentition (column chart), Figure S3: Graphical presentation of the result of the multiple comparison test during mastoid stimulation. Skull No. I on the left side in the analyzed dental conditions in selected frequency bands, Table S1: Basic statistics (mean $\pm \mathrm{SD}$, median $\left\langle\mathrm{Q}_{1} ; \mathrm{Q}_{3}\right\rangle$ ) of the velocity amplitude from the mastoid process of the skull No. I on the left side in the analyzed dental conditions in selected frequency bands and the result of the multiple comparison test.

Author Contributions: Conceptualization, S.B. and M.B.; methodology, S.B., M.B., and R.B.; software, K.D.; validation, S.B., M.B., and R.B.; formal analysis, M.B. and M.M.-K.; investigation, S.B., M.B. and M.M.-K.; resources, S.B., M.B., and R.B.; data curation, S.B., M.B., and M.M.-K.; writing-original draft preparation, S.B. and M.B.; writing-review and editing, M.B. and M.M.-K.; visualization, K.D. and R.B.; supervision, M.B.; project administration, S.B., M.B., and M.M.-K.; funding acquisition, S.B. and M.B. All authors have read and agreed to the published version of the manuscript.

Funding: This research received no external funding.

Conflicts of Interest: The authors declare no conflict of interest.

\section{References}

1. Eeg-Olofsson, M.; Stenfelt, S.; Granström, G. Implications for contralateral bone-conducted transmission as measured by cochlear vibrations. Otol. Neurotol. 2011, 32, 192-198. [CrossRef]

2. Stenfelt, S. Acoustic and physiologic aspects of bone conduction hearing. Adv. Otorhinolaryngol. 2011, 71, $10-21$.

3. Adelman, C.; Fraenkel, R.; Kriksunov, L.; Sohmer, H. Interactions in the cochlea between air conduction and osseous and non-osseous bone conduction stimulation. Eur. Arch. Otorhinolaryngol. 2012, 269, 425-429. [CrossRef]

4. Chordekar, S.; Kriksunov, L.; Kishon-Rabin, L.; Adelman, C.; Sohmer, H. Mutual cancellation between tones presented by air conduction, by bone conduction, and by non-osseous (soft tissue) bone conduction. Hear. Res. 2012, 283, 180-184. [CrossRef] [PubMed]

5. Ozer, E.; Adelman, C.; Freeman, S.; Sohmer, H. Bone conduction hearing on the teeth of the lower jaw. J. Basic Clin. Physiol. Pharmacol. 2002, 13, 89-96. [CrossRef] [PubMed]

6. Behn, A.; Westerberg, B.D.; Zhang, H.; Riding, K.H.; Ludemann, J.P.; Kozak, F.K. Accuracy of the Weber and Rinne tuning fork tests in evaluation of children with otitis media with effusion. Otolaryngology 2007, 36, 197-202. [CrossRef] [PubMed]

7. Miodonski, J. The technique of the Weber test. J. Laryngol. Otol. 1960, 74, 125-127. (In Polish) [CrossRef] [PubMed]

8. Brown, L.A. Dentaural hearing testing: Calibrating bone conduction through the teeth. Ann. Otol. Rhinol. Laryngol. 1969, 78, 1058-1061. [CrossRef]

9. Dahlin, G.C.; Allen, F.G.; Collard, E.W. Bone-conduction thresholds of human teeth. J. Acoust. Soc. Am. 1973, 53, 1434-1437. [CrossRef] [PubMed] 
10. Semczuk, B. Studies on the role of the state of dentition in the physiopathology of the auditory organ. III. Experimental studies on the effect of the state of dentition on bone sound conductivity through the skull. Ann. Univ. Mariae Curie Sklodowska Med. 1967, 22, 165-172.

11. Semczuk, B. Studies on the role of dentition in the physiopathology of the hearing organ. I. Clinical and statistical studies on the effect of dentition on the hearing organ and hearing in 5000 patients treated in an otolaryngologic clinic. Ann. Univ. Mariae Curie Sklodowska Med. 1966, 21, 167-174. [PubMed]

12. Semczuk, B. Studies on the role of the state of dentition in the physiopathology of the auditory organ. II. Comparative clinical studies on the state of hearing and dentition in 600 healthy persons of the same age from 35-50 years. Ann. Univ. Mariae Curie Sklodowska Med. 1967, 22, 153-163. [PubMed]

13. Schell, C.L.; Diehl, R.L.; Holmes, A.E.; Kubilis, P.S.; Loers, W.W.; Atchison, K.A.; Dolan, T.A. An association between dentate status and hearing acuity. Spec. Care Dent. 1999, 19, 208-213. [CrossRef]

14. Lawrence, H.P.; Garcia, R.I.; Essick, G.K.; Hawkins, R.; Krall, E.A.; Spiro, A., 3rd; Vokonas, P.S.; Kong, L.; King, T.; Koch, G.G. A longitudinal study of the association between tooth loss and age-related hearing loss. Spec. Care Dent. 2001, 21, 129-140. [CrossRef] [PubMed]

15. Peeters, J.; Naert, I.; Carette, E.; Manders, E.; Jacobs, R. A potential link between oral status and hearing impairment: Preliminary observations. J. Oral Rehabil. 2004, 31, 306-310. [CrossRef]

16. Kempf, H.G.; Roller, R.; Mühlbradt, L. Correlation between inner ear disorders and temporomandibular joint diseases. HNO 1993, 41, 7-10.

17. Pihut, M.; Majewski, P.; Wisniewska, G.; Reron, E. Auriculo-vestibular symptoms related to structural and functional disorders of the stomatognathic system. J. Physiol. Pharmacol. 2011, 62, 251-256.

18. King, W.H.; Burton, M.C.; Tucker, K.M. Clinical manifestations of dentaural hearing. J. Prosthet. Dent. 1974, 32, 130-140. [CrossRef]

19. Lee, Y.-R.; Choi, J.-S.; Kim, H.-E. Unilateral chewing as a risk factor for hearing loss: Association between chewing habits and hearing acuity. Tohoku J. Exp. Med. 2018, 246, 45-50. [CrossRef]

20. Nagasaka, H.; Matsukubo, T.; Takaesu, Y.; Kobayashi, Y.; Sato, T.; Ishikawa, T. Changes and equalization in hearing level induced by dental treatment and instruction in bilaterally equalized chewing: A clinical report. Bull. Tokyo Dent. Coll. 2002, 43, 243-250. [CrossRef]

21. Shreedhar, S.; Raza, F.; Vaidyanathan, A.K.; Veeravalli, P.T. Effect of an implant-retained complete overdenture on the hearing ability of edentulous patients: A clinical pilot study. J. Prosthet. Dent. 2020. [CrossRef] [PubMed]

22. Bochnia, M.; Porwolik, K.; Baliński, S.; Bolejko, R. A Device for Measuring Vibration of Human Skulls. Polish Patent PL W.122052, 13 January 2017.

23. Eeg-Olofsson, M. Transmission of Bone-Conducted Sound in the Human Skull Based on Vibration and Perceptual Measures. Master's Thesis, University of Gothenburg, Gothenburg, Sweden, 2012.

24. Håkansson, B.; Brandt, A.; Carlsson, P.; Tjellström, A. Resonant frequencies of the human skull in vivo. J. Acoust. Soc. Am. 1994, 95, 1474-1481. [CrossRef] [PubMed]

25. Khalil, T.B.; Viano, D.C.; Smith, D.L. Experimental analysis of the vibrational characteristics of the human skull. J. Sound. Vib. 1979, 63, 351-376. [CrossRef]

26. Bochnia, M. Studies of the Dynamics of General Vibration on the Organ of Corti; Oficyna Wydawnicza Politechniki Wroclawskiej: Wroclaw, Poland, 2001; pp. 307-311. (In Polish)

27. Stenfelt, S.; Goode, R.L. Bone-conducted sound: Physiological and clinical aspects. Otol. Neurotol. 2005, 26, 1245-1261. [CrossRef]

28. Stenfelt, S.; Goode, R.L. Transmission properties of bone-conducted sound: Measurements in cadaver heads. J. Acoust. Soc. Am. 2005, 118, 2373-2391. [CrossRef]

29. Eeg-Olofsson, M.; Stenfelt, S.; Taghavi, H.; Reinfeldt, S.; Håkansson, B.; Tengstrand, T.; Finizia, C. Transmission of bone-conducted sound-Correlation between hearing perception and cochlear vibration. Hear. Res. 2013, 306, 11-20. [CrossRef]

30. Franke, E.K. Response of the human skull to mechanical vibrations. J. Acoust. Soc. Am. 1956, 28, 1277-1284. [CrossRef]

31. Gurdjian, E.S.; Hodgson, V.R.; Thomas, I.M. Studies on mechanical impedance of the human skull: Preliminary report. J. Biomech. 1970, 3, 239-247. [CrossRef]

32. Håkansson, B.; Carlsson, P.; Tjellström, A. The mechanical point impedance of the human head, with and without skin penetration. J. Acoust. Soc. Am. 1986, 80, 1065-1075. [CrossRef] 
33. Eeg-Olofsson, M.; Stenfelt, S.; Tjellström, A.; Granström, G. Transmission of bone-conducted sound in the human skull measured by cochlear vibrations. Int. J. Audiol. 2008, 47, 761-769. [CrossRef] [PubMed]

34. Semczuk, B. Studies on the role of the state of dentition in the physiopathology of the auditory organ. IV. Studies on the effect of dentition on the etiology of acoustic trauma. Ann. Univ. Mariae Curie Sklodowska Med. 1967, 22, 173-178. [PubMed]

35. Ceypek, T.; Kuźniar, Z.J. The significance of limited frequency bands for understanding Polish speech. Otolaryngol. Pol. 1970, 24, 429-433. (In Polish) [PubMed]

36. Nowicki, J. Polish speech intelligibility depending on the frequency band. Otolaryng. Pol. 1972, 26, 7-14. (In Polish)

37. McLeod, R.W.J.; Roberts, W.H.; Perry, I.A.; Richardson, B.E.; Culling, J.F. Scanning laser Doppler vibrometry of the cranium when stimulated by a B71 bone transduce. Appl. Acoust. 2018, 142, 53-58. [CrossRef]

38. Dobrev, I.; Stenfelt, S.; Röösli, C. Influence of stimulation position on the sensitivity for bone conduction hearing aids without skin penetration. Int. J. Audiol. 2016, 55, 439-446. [CrossRef]

39. Stenfelt, S.; Håkansson, B.; Tjellström, A. Vibration characteristics of bone conducted sound in vitro. J. Acoust. Soc. Am. 2000, 107, 422-431. [CrossRef]

40. Eeg-Olofsson, M.; Granstrom, G.; Håkansson, B.; Stenfelt, S.; Tjellstrom, A. Implanterbar BAHA. Acta Soc. Med. Suec. 2002, 111, 265.

41. Hoffman, B.; Lorens, G. Dental problems cause hearing loss. Sluch 2010, 72, 8. (In Polish)

(C) 2020 by the authors. Licensee MDPI, Basel, Switzerland. This article is an open access article distributed under the terms and conditions of the Creative Commons Attribution (CC BY) license (http://creativecommons.org/licenses/by/4.0/). 